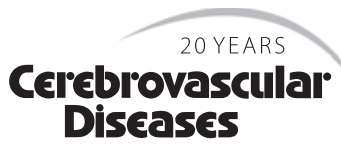

20 YEARS

Diseases

\title{
Gender Differences in Outcomes after \\ Ischemic Stroke: Role of Ischemic Lesion Volume and Intracranial Large-Artery Occlusion
}

\author{
Gisele S. Silva ${ }^{\mathrm{a}}$ e Fabricio O. Lima ${ }^{\mathrm{a}}$ Erica C.S. Camargo ${ }^{\mathrm{a}}$ Wade S. Smith ${ }^{\mathrm{c}}$ \\ Michael H. Lev ${ }^{b} \quad$ Gordon J. Harris $^{\mathrm{b}} \quad$ Elkan F. Halpern ${ }^{\mathrm{b}} \quad$ Walter Koroshetz $^{\mathrm{d}}$ \\ Karen L. Furie ${ }^{a}$ \\ Departments of a Neurology and ${ }^{\mathrm{b}}$ Radiology, Massachusetts General Hospital and Harvard Medical School, Boston, \\ Mass., ' Department of Neurology, University of California at San Francisco, San Francisco, Calif., and d National

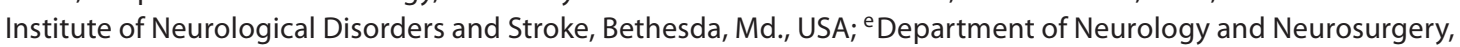 \\ Federal University of São Paulo, São Paulo, Brazil
}

\section{Key Words}

Sex differences $\cdot$ Ischemic stroke $\cdot \mathrm{CT}$ angiography

\begin{abstract}
Background: The reasons for gender disparities in stroke outcome remain unclear, and little is known about the value of acute neuroimaging characteristics in elucidating differential stroke outcomes between the sexes. Methods: We prospectively evaluated consecutive patients with acute ischemic stroke. CT angiography (CTA) was performed in all patients within $24 \mathrm{~h}$ of symptom onset. CTA source images were used to evaluate lesion volume. The primary outcome measure was a modified Rankin scale (mRS) score $\geq 3$ at 6 months. Results: We evaluated 676 consecutive patients (322 women). Women were older than men $(p<0.01)$, more frequently had a prestroke $m R S>0(p<0.01)$, and had higher admission National Institutes of Health Stroke scale scores $(p=0.01)$. More women had intracranial artery occlusions than men ( 46 vs. $33.1 \%, p=0.01$ ), but there was no significant difference between ischemic lesion volumes $(p=0.21)$. Using multiple regression, female gender remained an independent predictor of poor mRS scores at 6 months (odds ratio $1.57 ; 95 \%$ confidence interval 1.02-2.36) after adjustment for
\end{abstract}

clinical and imaging covariates. Conclusion: Compared with men, women are less likely to achieve independence after acute ischemic stroke. The disparity in stroke outcome is not explained by differences in ischemic lesion volume or the presence of intracranial artery occlusions.

Copyright $\odot 2010$ S. Karger AG, Basel

\section{Introduction}

Because women have, on average, a longer life expectancy than men, and stroke incidence increases with age, older female patients are likely to bear the major burden of stroke-related mortality and disability $[1,2]$. Indeed, after controlling for variables such as age, comorbidities, prestroke functional status and stroke severity, more women than men require institutional care after a stroke [3-6]. The reasons for the disparities in stroke outcome related to gender are still unclear $[4,7-9]$.

Many of the studies that have evaluated sex differences in acute stroke presentation, treatment and outcomes have combined patients with hemorrhagic and ischemic strokes $[3,8-10]$. The determinants of prognosis in hemorrhagic and ischemic strokes are different, and analyz-

\section{KARGER}

(C) 2010 S. Karger AG, Basel

Fax +41 613061234 E-Mail karger@karger.ch www.karger.com www.karger.com/ced
Gisele Silva, $\mathrm{MD}, \mathrm{PhD}$

741 Altino Arantes Ave., apt 81

São Paulo, SP 04042-033 (Brazil)

Tel. +55 118358 0583, Fax +55 1150832172

E-Mail giselesampaio@hotmail.com 
ing them together may lead to erroneous conclusions. In ischemic stroke, age, treatment with intravenous recombinant tissue plasminogen activator (rt-PA), admission National Institute of Health Stroke scale (NIHSS) score, ischemic lesion volume, and the presence of an intracranial large-artery occlusion are independent predictors of long-term functional outcomes [11-15].

The extent to which neuroimaging characteristics such as ischemic lesion volume and intracranial largeartery occlusion add to known determinants of prognosis after ischemic stroke in explaining gender disparity in outcome has not been previously investigated. We hypothesized that women were more likely to have larger infarct volumes and a higher prevalence of intracranial large-vessel occlusions, which might be independent neuroimaging prognostic markers.

\section{Patients and Methods}

We evaluated consecutive patients enrolled in a prospective cohort study at two university-based hospitals from March 2003 to December 2005. Noncontrast CT scans (NCCT) and CT angiograms (CTA) were performed for acute ischemic stroke within $24 \mathrm{~h}$ from symptom onset or from last seen well. Patients with primary intracranial hemorrhage and those in whom iodinated contrast agent administration was contraindicated were excluded. Data collected included demographics, presence of stroke risk factors, circumstances of stroke onset, NIHSS scores, modified Rankin scale scores (mRS; before stroke and at 6 months), Stop Stroke Study-TOAST (SSS-TOAST) classification, neuroimaging characteristics and thrombolysis status [16]. The prospective study received institutional review board approval. All participants gave written informed consent.

\section{Neuroimaging Protocol}

NCCT and CTA acquisitions were performed with 16- or 64-section multidetector CT scanners (LightSpeed; GE Healthcare, Milwaukee, Wisc., USA). Representative sample parameters were: $120-140 \mathrm{kVp}, 170 \mathrm{~mA}, 2$ s scan time, and $5 \mathrm{~mm}$ section thickness for NCCT and $2.5 \mathrm{~mm}$ section thickness for CTA source images (CTA-SIs). NCCT imaging was immediately followed by biphasic helical scanning. CTA was performed after a 25 -second delay (40 s for patients in atrial fibrillation) and intravenous administration of $100-140 \mathrm{ml}$ of a nonionic contrast agent (Isovue; Bracco Diagnostics, Princeton, N.J., USA) at a rate of $3 \mathrm{ml} / \mathrm{s}$ by power injector (Medrad Power Injector; Medrad, Indianola, Pa., USA). Parameters were $140 \mathrm{kVp}, 220-250 \mathrm{~mA}, 0.8-1.0$ s rotation time, $2.5 \mathrm{~mm}$ section thickness, $1.25 \mathrm{~mm}$ reconstruction interval, $3.75 \mathrm{~mm}$ per rotation table speed, and 0.75:1 pitch. CTA-SIs were reconstructed into standardized maximum-intensity projection views of the intracranial and extracranial vasculature. CT and CTA images were analyzed in consensus by a neuroradiologist and two neurologists experienced in stroke neuroimaging. CTASIs were evaluated for the presence of ischemic regions by identifying areas of relative hypoattenuation. Using a semiautomated software package (Alice; Parexel, Waltham, Mass., USA), these ischemic regions of interest were visually segmented to determine total lesion volume [17]. CTA was used to assess for intracranial arterial occlusions. Large-vessel intracranial occlusions amenable to intra-arterial neurointerventional approaches were defined as middle cerebral artery (M1 or proximal M2), internal carotid artery, or basilar occlusions when those arteries were the culprits for the acute stroke [18].

\section{Statistical Analysis}

Means and standard deviations or medians and interquartile intervals were used to describe patients' characteristics. The independent samples t test was used to compare means between men and women. Nonparametric data were compared using the Mann-Whitney test. Categorical variables were compared with the $\chi^{2}$ test or Fisher's exact test. We used multiple logistic regression to investigate the influence of gender upon 6-month mRS scores dichotomized at $2(\mathrm{mRS} \leq 2$ vs. $\geq 3)$. All variables that showed an association in the univariate analysis with a $\mathrm{p} \leq 0.1$ were included in the multivariate analysis. A 2 -tailed $\mathrm{p}<0.05$ was considered statistically significant. Statistical analysis was performed with SPSS 15.0 software (Chicago, Ill., USA).

\section{Results}

We evaluated 676 consecutive patients with acute ischemic stroke, of whom $322(48 \%)$ were women. Women were older $(\mathrm{p}<0.01)$, more often had a prestroke mRS greater than $0(\mathrm{p}<0.01)$, were more likely to have an unknown time of symptom onset $(\mathrm{p}=0.03)$ and had a higher prevalence of atrial fibrillation $(\mathrm{p}<0.01)$ and hypertension $(\mathrm{p}<0.01)$. Stroke mechanisms varied by sex, with more women having cryptogenic embolic events $(\mathrm{p}<$ 0.01 ). Baseline characteristics stratified by sex are presented in table 1 .

NIHSS scores at admission were higher in women (median 6 [2-13] vs. 4 [2-11], $\mathrm{p}=0.01$ ). There were no differences between genders in time to first neuroimaging, lesion volumes on CTA-SI or rates of treatment with intravenous or intra-arterial thrombolysis. Large-artery intracranial occlusions were more prevalent in women (46 vs. $33.1 \%, p=0.01$ ) (table 2). The rates of intensive care unit admission, pneumonia, and deep-venous thrombosis during admission were similar in men and women. Urinary tract infections were more common in women $(\mathrm{p}<0.01$; table 3$)$.

We obtained follow-up data in 597 patients (88.3\%) at 6 months. Mortality rates were not different between men and women. Two-hundred and twenty patients (32.5\%) had a poor outcome (mRS 3-6), 133 (41.3\%) were women and $87(24.6 \%)$ were men $(\mathrm{p}<0.01)$. Age, prestroke $\mathrm{mRS}$, gender, marital status, history of hypertension, atrial fibrillation, diabetes, ischemic lesion volume, presence of 
Table 1. Baseline characteristics of patients by gender

\begin{tabular}{|c|c|c|c|}
\hline & Female $(n=322)$ & Male $(\mathrm{n}=354)$ & $\mathrm{p}$ \\
\hline Age (means $\pm S D)$, years & $72.2 \pm 15.8$ & $65 \pm 13.9$ & $<0.01$ \\
\hline $\mathrm{mRS}>0$ at baseline, $\%$ & 35.2 & 24 & $<0.01$ \\
\hline \multicolumn{4}{|l|}{ Marital status } \\
\hline Widowed, \% & 37.5 & 5.1 & $<0.01$ \\
\hline Married, \% & 38.4 & 75.5 & $<0.01$ \\
\hline Single, $\%$ & 10.6 & 9.1 & 0.51 \\
\hline Divorced, \% & 11.7 & 7.7 & 0.16 \\
\hline Unknown, \% & 2.2 & 2.6 & 0.75 \\
\hline Unknown time of symptom onset ${ }^{1}, \%$ & 42 & 34.2 & 0.04 \\
\hline Hypertension, \% & 66.8 & 56.8 & $<0.01$ \\
\hline Diabetes, $\%$ & 18.3 & 18.1 & 0.93 \\
\hline Dyslipidemia, \% & 27.6 & 29.4 & 0.61 \\
\hline Atrial fibrillation, $\%$ & 25.2 & 18.6 & 0.04 \\
\hline Previous stroke, $\%$ & 7.5 & 4.8 & 0.14 \\
\hline Coronary artery disease, $\%$ & 15.5 & 29.9 & $<0.01$ \\
\hline Current smoker, \% & 11.2 & 21.5 & $<0.01$ \\
\hline \multicolumn{4}{|l|}{ SSS-TOAST } \\
\hline Cardioembolic, \% & 39.2 & 39.1 & 0.96 \\
\hline Small vessel, \% & 9.8 & 9.2 & 0.79 \\
\hline Large artery, \% & 12 & 19.8 & $<0.01$ \\
\hline Undetermined: cryptogenic emboli, \% & 12.7 & 4.3 & $<0.01$ \\
\hline Undetermined: no embolus, \% & 8.2 & 12.1 & 0.1 \\
\hline Undetermined: incomplete investigation, \% & 3.2 & 3.4 & 0.84 \\
\hline More than one mechanism, $\%$ & 7.3 & 4.6 & 0.14 \\
\hline Other, $\%$ & 6.6 & 7.2 & 0.14 \\
\hline
\end{tabular}

mRS $=$ Modified rankin scale; SSS-TOAST $=$ Stop Stroke Study-TOAST

${ }^{1}$ Stroke symptoms on awake or unknown onset time due to lack of a witness when the patient was unable to determine time from symptom onset.

Table 2. Intracranial occlusions on CTA according to gender

\begin{tabular}{lllr}
\hline & $\begin{array}{l}\text { Female } \\
(\mathrm{n}=322)\end{array}$ & $\begin{array}{l}\text { Male } \\
(\mathrm{n}=354)\end{array}$ & $\mathrm{p}$ \\
\hline Any intracranial occlusion $^{1}$ & $46 \%$ & $33.1 \%$ & $<0.01$ \\
Middle cerebral artery M1 $_{\text {Middle cerebral artery M2 }}$ & $24.2 \%$ & $16.4 \%$ & 0.01 \\
Internal carotid artery $_{\text {T occlusion }}$ & $23.9 \%$ & $17.2 \%$ & 0.03 \\
Basilar & $30.7 \%$ & $22.3 \%$ & 0.01 \\
\hline
\end{tabular}

${ }^{1} \mathrm{M} 1$, proximal M2, internal carotid artery (including T lesions) or basilar occlusions. Some patients had occlusions of more than one artery. intracranial large-artery occlusion, admission NIHSS and treatment with intravenous or intra-arterial thrombolysis were all univariate predictors of mRS scores at 6 months (table 4). Female sex remained an independent predictor of a poor mRS score at 6 months (odds ratio
1.57; 95\% confiedence interval 1.03-2.36, $\mathrm{p}=0.04$ ) after adjustment for all factors identified in the univariate analyses (fig. 1). Age, prestroke mRS, admission NIHSS scores and ischemic lesion volume on CTA-SI were also predictors of poor outcome (fig. 1). 
Table 3. Acute stroke characteristics, treatment, complication and outcomes by gender

\begin{tabular}{|c|c|c|c|}
\hline & Female & Male & $\mathrm{p}$ \\
\hline NIHSS score (median) & $6(2-13)$ & $4(2-11)$ & 0.01 \\
\hline CTA-SI volumes (median), $\mathrm{cm}^{3}$ & $23.73(0-184.19)$ & $13.21(0-150.88)$ & 0.21 \\
\hline Intracranial occlusion, $\%$ & 46 & 33.1 & 0.01 \\
\hline Time to first neuroimaging (means $\pm \mathrm{SD}$ ), $\mathrm{h}$ & $6.73 \pm 7.94$ & $7.45 \pm 7.96$ & 0.27 \\
\hline IV thrombolysis, \% & 17.3 & 14.8 & 0.36 \\
\hline IA thrombolysis, $\%$ & 6.2 & 4.8 & 0.32 \\
\hline ICU admission, \% & 33.5 & 30.2 & 0.35 \\
\hline Pneumonia, \% & 5 & 7.1 & 0.26 \\
\hline Deep-vein thrombosis, $\%$ & 0.3 & 0.8 & 0.36 \\
\hline Urinary tract infection, $\%$ & 10.6 & 2.9 & $<0.01$ \\
\hline Symptomatic intracranial hemorrhage ${ }^{1}, \%$ & 2.8 & 3.1 & 0.92 \\
\hline Asymptomatic intracranial hemorrhage ${ }^{1}, \%$ & 4.2 & 6.2 & 0.61 \\
\hline Mortality at 6 months, $\%$ & 12.28 & 8.54 & 0.13 \\
\hline Living home independent at 6 months, $\%$ & 49.4 & 66.9 & $<0.01$ \\
\hline mRS (3-6) at 6 months, $\%$ & 41.3 & 24.6 & $<0.01$ \\
\hline
\end{tabular}

Figures in parentheses represent 25 and 75 interquartile intervals. CTA-SI = CT angiography source image; IV = intravenous; IA intra-arterial; ICU = intensive care unit. ${ }^{1}$ Only patients treated with intravenous or intra-arterial thrombolysis.

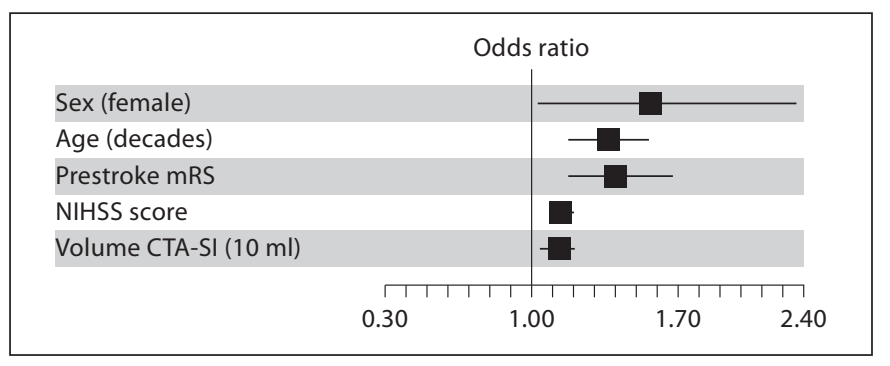

Fig. 1. Factors independently associated with functional outcome (mRS scores 3-6 at 6 months) on a multivariate logistic regression model.

\section{Discussion}

We found that women with acute ischemic stroke were older and more commonly widowed than men, had a higher prevalence of prestroke disability, of intracranial arterial occlusions and of uncertain time of stroke onset; they also had higher admission NIHSS scores and a worse functional outcome. After adjusting for other predictors of functional outcome, female sex was still an independent predictor of poor prognosis at 6 months. Our findings are consistent with previous studies, which have shown that compared to men, women with stroke tend to be older, are less likely to emerge independent or be discharged home $[3,4,10,19,20]$.
Table 4. Univariate predictors of poor functional status (mRS scale 3-6) at 6 months

\begin{tabular}{llc}
\hline Variable & OR $(95 \% \mathrm{CI})$ & $\mathrm{p}$ \\
\hline Age & $1.47(1.30-1.67)$ & $<0.01$ \\
Pre-stroke mRS & $1.50(1.29-1.73)$ & $<0.01$ \\
Female sex & $2.21(1.58-3.11)$ & $<0.01$ \\
Marital status & & \\
$\quad$ Married-partner & $0.61(0.43-0.85)$ & $<0.01$ \\
$\quad$ Unknown & $0.56(0.15-2.11)$ & 0.39 \\
$\quad$ Divorced & $0.54(0.28-1.04)$ & 0.07 \\
$\quad$ Widowed $\quad 3.45(2.29-5.20)$ & $<0.01$ \\
$\quad$ Single & $0.67(0.37-1.20)$ & 0.17 \\
Diabetes & $1.75(1.15-2.65)$ & $<0.01$ \\
Atrial fibrillation & $2.00(1.37-2.99)$ & $<0.01$ \\
Coronary artery disease & $1.29(0.8-1.8)$ & 0.2 \\
Hypertension & $1.56(1.10-2.22)$ & 0.01 \\
Dyslipidemia & $0.91(0.628-1.32)$ & 0.91 \\
Admission NIHSS & $1.14(1.11-1.17)$ & $<0.01$ \\
Time to first neuroimaging & $0.99(0.96-1.017)$ & 0.99 \\
Intracranial occlusion & $2.89(2.05-4.08)$ & $<0.01$ \\
Volumes CTA-SI (10 cm $\left.{ }^{3}\right)$ & $1.22(1.15-1.31)$ & $<0.01$ \\
IV thrombolysis & $1.7(1.13-2.6)$ & 0.01 \\
IA thrombolysis & $4.08(1.8-9.1)$ & $<0.01$ \\
\hline
\end{tabular}

mRS = Modified Rankin scale; CTA-SI = CT angiography source image; IV = intravenous; IA = intra-arterial. 
Among our patients, women had higher NIHSS scores at presentation, but similar ischemic lesion volumes when compared to men. Their increased neurologic deficits at presentation might have been partly explained by a higher frequency of previous stroke. There were no differences in the time to first neuroimaging, or in the rates of intravenous or intra-arterial thrombolysis between men and women. Our data support previous studies that found no difference in intravenous rt-PA utilization between men and women during the treatment window [21, 22]. However, several other studies have reported that females are less frequently treated with intravenous rt-PA after multivariable adjustment $[3,23,24]$.

Our study is the first to report a higher prevalence of intracranial large-artery occlusion at stroke presentation in women. Despite this, ischemic lesion volumes were not different between men and women, raising interesting hypotheses concerning potential differences in collateralization and infarct growth. A recent publication showed that in patients treated with intravenous rt-PA, the frequency of residual arterial occlusion is higher in males and that women had a trend to a higher frequency of large territorial infarcts although neither ischemic lesion volume nor the rates of intracranial large-artery occlusion before thrombolysis were described [25]. A higher recanalization rate after intravenous rt-PA in women, as well as a higher response rate to intra-arterial thrombolysis, was also described $[26,27]$. A pooled analysis of randomized controlled trials showed a greater benefit for intravenous thrombolysis in women and nullification of the usual gender difference in outcome [28]. The considerable frequency of intracranial occlusions and the worse prognosis of women after stroke in our patients confer even more importance to the use of recanalization therapies in females.

Our study has some limitations. First, no gold-standard tests (magnetic resonance imaging with diffusionweighted imaging or follow-up CT scans) were used to verify ischemic lesion volumes. Nevertheless, CTA-SIs correlate with lesion volumes on diffusion-weighted imaging and may have advantages over other techniques because CTA-SIs cover the entire brain and are available at the completion of imaging [17]. Secondly, factors not included in our analysis that could partially explain gender disparity in outcome after acute ischemic stroke include poststroke depression, degree of social support, biological effects of gender as a modulator of ischemic cell death and baseline frequency of silent brain injury (e.g. silent infarcts, white matter disease, atrophy) [29-32].

In conclusion, women less frequently achieve independence after acute ischemic stroke independent of admission NIHSS scores, age, ischemic volumelesion, prestroke $\mathrm{mRS}$, and the presence of intracranial large-vessel occlusion. A better understanding of the causes of gender disparities in ischemic stroke, including risk factors, stroke mechanisms, response to acute stroke therapies, and recovery will hopefully lead to better outcomes in both sexes in the future.

\section{Acknowledgements}

Sources of funding: supported by Agency for Healthcare Research and Quality grant AHRQ R01 HS11392 and National Institutes of Health grant P50NS051343. We gratefully acknowledge the support of the Deane Institute for Integrative Research in Stroke and Atrial Fibrillation and the Lakeside Foundation.

\section{References}

1 Reeves MJ, Bushnell CD, Howard G, Gargano JW, Duncan PW, Lynch G, Khatiwoda A, Lisabeth L: Sex differences in stroke: epidemiology, clinical presentation, medical care, and outcomes. Lancet Neurol 2008;7:915-926.

-2 Bushnell CD, Hurn P, Colton C, Miller VM, del Zoppo G, Elkind MSV, Herrington D, Gwendolyn FL, Gorelick P, James A, Brown CM, Choi E, Bray P, Newby LK, Goldstein LB, Simpkins J: Advancing the study of stroke in women: summary and recommendations for future research from an NINDSsponsored multidisciplinary working group. Stroke 2006;37:2387-2399
-3 Gargano JW, Reeves MJ: Sex differences in stroke recovery and stroke-specific quality of life: results from a statewide stroke registry. Stroke 2007;38:2541-2548.

4 Gargano JW, Wehner S, Reeves M: Sex differences in acute stroke care in a statewide stroke registry. Stroke 2008;39:24-29.

5 Niewada M, Kobayashi A, Sandercock PAG, Kamiński B, Członkowska A: Influence of gender on baseline features and clinical outcomes among 17,370 patients with confirmed ischaemic stroke in the international stroke trial. Neuroepidemiology 2005;24 $123-128$
-6 Glader E, Stegmayr B, Norrving B, Terént A, Hulter-Asberg K, Wester P, Asplund K: Sex differences in management and outcome after stroke: a Swedish national perspective. Stroke 2003;34:1970-1975.

7 Reeves MJ, Fonarow GC, Zhao X, Smith EE, Schwamm LH: Quality of care in women with ischemic stroke in the GWTG program. Stroke 2009;40:1127-1133.

-8 Labiche LA, Chan W, Saldin KR, Morgenstern LB: Sex and acute stroke presentation. Ann Emerg Med 2002;40:453-460.

9 Gargano JW, Wehner S, Reeves MJ: Do presenting symptoms explain sex differences in emergency department delays among patients with acute stroke? Stroke 2009;40:1114-1120. 
10 Roquer J, Campello AR, Gomis M: Sex differences in first-ever acute stroke. Stroke 2003;34:1581-1585.

-11 Heuschmann PU, Kolominsky-Rabas PL, Roether J, Misselwitz B, Lowitzsch K, Heidrich J, Hermanek P, Leffmann C, Sitzer M, Biegler M, Buecker-Nott H, Berger K: Predictors of in-hospital mortality in patients with acute ischemic stroke treated with thrombolytic therapy. JAMA 2004;292: 1831-1838.

-12 Tissue plasminogen activator for acute ischemic stroke. The National Institute of Neurological Disorders and Stroke rt-PA Stroke Study Group. N Engl J Med 1995;333:15811587.

13 Adams HP, Davis PH, Leira EC, Chang KC, Bendixen BH, Clarke WR, Woolson RF, Hansen MD: Baseline NIH stroke scale score strongly predicts outcome after stroke: a report of the trial of org 10172 in acute stroke treatment (TOAST). Neurology 1999;53: 126-131.

14 Ois A, Cuadrado-Godia E, Jiménez-Conde J, Gomis M, Rodríguez-Campello A, Martínez-Rodríguez JE, Munteis E, Roquer J: Early arterial study in the prediction of mortality after acute ischemic stroke. Stroke 2007;38:2085-2089.

15 Lövblad KO, Baird AE, Schlaug G, Benfield A, Siewert B, Voetsch B, Connor A, Burzynski C, Edelman RR, Warach S: Ischemic lesion volumes in acute stroke by diffusionweighted magnetic resonance imaging correlate with clinical outcome. Ann Neurol 1997;42:164-170.

16 Ay H, Benner T, Arsava EM, Furie KL, Singhal $A B$, Jensen $M B$, Ayata $C$, Towfighi $A$, Smith EE, Chong JY, Koroshetz WJ, Sorensen AG: A computerized algorithm for etiologic classification of ischemic stroke: the Causative Classification of Stroke System. Stroke 2007;38:2979-2984.
17 Camargo ECS, Furie KL, Singhal AB, Roccatagliata L, Cunnane ME, Halpern EF, Harris GJ, Smith WS, Gonzalez RG, Koroshetz WJ, Lev MH: Acute brain infarct: detection and delineation with CT angiographic source images versus nonenhanced CT scans. Radiology 2007;244:541-548.

18 Smith WS, Sung G, Saver J, Budzik R, Duckwiler G, Liebeskind DS, Lutsep HL, Rymer MM, Higashida RT, Starkman S, Gobin YP, Frei D, Grobelny T, Hellinger F, Huddle D, Kidwell C, Koroshetz W, Marks M, Nesbit G, Silverman IE: Mechanical thrombectomy for acute ischemic stroke: final results of the Multi MERCI trial. Stroke 2008;39:12051212.

19 Kapral MK, Fang J, Hill MD, Silver F, Richards J, Jaigobin C, Cheung AM: Sex differences in stroke care and outcomes: results from the Registry of the Canadian Stroke Network. Stroke 2005;36:809-814.

-20 Di Carlo A, Lamassa M, Baldereschi M, Pracucci G, Basile AM, Wolfe CDA, Giroud M Rudd A, Ghetti A, Inzitari D: Sex differences in the clinical presentation, resource use, and 3-month outcome of acute stroke in $\mathrm{Eu}$ rope: data from a multicenter multinational hospital-based registry. Stroke 2003;34: 1114-1119.

21 Eriksson M, Glader E, Norrving B, Terént A Stegmayr B: Sex differences in stroke care and outcome in the Swedish national quality register for stroke care. Stroke 2009;40:909914.

22 Smith DB, Murphy P, Santos P, Phillips M, Wilde M: Gender differences in the Colorado Stroke Registry. Stroke 2009;40:10781081.

23 Foerch C, Misselwitz B, Humpich M, Steinmetz H, Neumann-Haefelin T, Sitzer M: Sex disparity in the access of elderly patients to acute stroke care. Stroke 2007;38:2123-2126.

-24 Reid JM, Dai D, Gubitz GJ, Kapral MK, Christian C, Phillips SJ: Gender differences in stroke examined in a 10-year cohort of patients admitted to a Canadian teaching hospital. Stroke 2008;39:1090-1095.
25 Förster A, Gass A, Kern R, Wolf ME, Ottomeyer C, Zohsel K, Hennerici M, Szabo K: Gender differences in acute ischemic stroke: etiology, stroke patterns and response to thrombolysis. Stroke 2009;40:2428-2432.

-26 Savitz SI, Schlaug G, Caplan L, Selim M: Arterial occlusive lesions recanalize more frequently in women than in men after intravenous tissue plasminogen activator administration for acute stroke. Stroke 2005;36: 1447-1451.

27 Hill MD, Kent DM, Hinchey J, Rowley H, Buchan AM, Wechsler LR, Higashida RT, Fischbein NJ, Dillon WP, Gent M, Firszt CM, Schulz GA, Furlan AJ: Sex-based differences in the effect of intra-arterial treatment of stroke: analysis of the PROACT-2 study. Stroke 2006;37:2322-2325.

28 Kent DM, Price LL, Ringleb P, Hill MD, Selker HP: Sex-based differences in response to recombinant tissue plasminogen activator in acute ischemic stroke: a pooled analysis of randomized clinical trials. Stroke 2005;36: 62-65.

29 Boden-Albala B, Litwak E, Elkind MSV, Rundek T, Sacco RL: Social isolation and outcomes post stroke. Neurology 2005;64: 1888-1892.

-30 Eriksson M, Asplund K, Glader E, Norrving B, Stegmayr B, Terént A, Asberg KH, Wester P: Self-reported depression and use of antidepressants after stroke: a national survey. Stroke 2004;35:936-941.

-31 Li H, Pin S, Zeng Z, Wang MM, Andreasson KA, McCullough LD: Sex differences in cell death. Ann Neurol 2005;58:317-321.

-32 van den Heuvel DM, Admiraal-Behloul F, ten Dam VH, Olofsen H, Bollen EL, Murray HM, Blauw GJ, Westendorp RG, de Craen AJM, van Buchem MA: Different progression rates for deep white matter hyperintensities in elderly men and women. Neurology 2004;63:1699-1701. 